\title{
Seismic damage assessment of a historical masonry minaret considering soil-structure interaction
}

\author{
Taha Yasin Altıo* ${ }^{*}$, Ali Demir iD \\ Manisa Celal Bayar University, Department of Civil Engineering, Manisa, Turkey
}

\begin{abstract}
Historical structures should be carefully preserved and transferred to the next generations. Therefore, their seismic performances should be investigated in detail. In the finite element method, many parameters affect the seismic behaviour and damage distribution in the structures. One of the most significant parameters is the Soil-Structure Interaction effect. In finite element analyses, the soil medium is generally neglected, and the structures' base is restrained by fixed supports. In this study, seismic response of a historical masonry minaret is investigated by considering the Soil-Structure Interaction and Operational Modal Analysis methods. To determine the effect of Soil-Structure Interaction on structural behaviour, the fixed supports, hard and soft soil mediums at the base of the structure are modelled. The material and failure behaviours are defined with the Concrete Damage Plasticity model. Displacements, principal stresses, damage rates, and damage distribution of models are obtained with nonlinear time history analyses. According to the results, the interstory drift increases due to the decrease in the stiffness of the soil media. In addition, the fixed supports model was damaged more tensile stress damage than the other models. The least occurred in the soft soil model. It is concluded that the Soil-Structure Interaction effect significantly affects structural behaviour, especially the damage rate and distribution.
\end{abstract}

\section{Keywords}

Soil-structure interaction; Damage plasticity; Nonlinear dynamic analysis; Historical minaret; Seismic performance

Received: 14 August 2021; Accepted: 15 September 2021

ISSN: 2630-5763 (online) C 2021 Golden Light Publishing All rights reserved.

\section{Introduction}

Historical structures are among the most significant cultural heritages that need to be handed down to the next generations. However, these structures are subjected to devastating effects such as wars, earthquakes, floods, fire, explosions, chemical effects, and ground problems during their long life. It is a social responsibility to protect historical structures. In severe earthquakes, it has been seen that slender structures such as minarets and towers could be seriously damaged. To safely hand down such significant structures to the next generations, their seismic performances should be realistically determined. If necessary, the structures should be strengthened with appropriate methods [1].

Destructive and non-destructive tests are performed to determine the properties of the structural material. Destructive tests are generally not used for significant cultural structures. For this reason, researchers have focused on the Operational Modal Analysis (OMA) method, which is one of the leading non-destructive tests in recent years. OMA

\footnotetext{
Corresponding author

Email: taha.altiok@,cbu.edu.tr
} 
is a modal analysis method. In this method, the response signals of the structure against natural vibration effects such as wind and traffic are measured with accelerometers placed in critical areas of the structure. After the obtained signals are collected in data collection devices, the dynamic characteristics of the structure are determined by techniques with different algorithms such as the Enhanced Frequency Domain Decomposition technique (EFDD) and the Stochastic Subspace Identification technique. OMA is frequently used in bridges [2], silos [3], nuclear structures [4], high structures, historical structures [5-10] and many other fields [11]. Altunışık et al. [5] investigated Kaya Celebi Mosque's seismic behaviour in Turkey using experimental and numerical methods. They predicted structural safety by comparing the dynamic parameters with the boundary conditions in the seismic code. Demir et al. [7] improved the historical Hafsa Sultan mosque's initial young's modulus by using the OMA method. Linear Time History (LTH) and Non-linear Time History (NLTH) analyses of this mosque were performed before and after improvement. Gani et al. [12] investigated the structural performance of Davutpaşa barracks in Turkey with the finite element (FE) method. They determined that the existing damages resulted from ground problems and dynamic effects. Hökelekli et al. [13] calibrated the initial mechanical properties of a historical masonry minaret using OMA method. LTH and NLTH damage analyses were performed. Rashidi et al. [14] used the OMA method to evaluate the effects of different infill wall materials on the dynamic properties of modular steel units. Aloisio et al. [15] studied the effect of strengthening on the structural dynamic characteristics of a masonry palace using the OMA method. Foti et al. [16] calibrated the FE models of two strategic structures using the OMA method. Güneş et al. [17] determined the dynamic characteristics of a masonry structure, consisting of damping ratio, natural frequency, and mode shapes, using the OMA method.

One of the most significant factors affecting the seismic behavior of the structures is the soil medium. In the literature, it is generally assumed that the structure's base is restrained with fixed supports, neglecting the soil medium $[6,7,9,10,18]$. Although this assumption is acceptable for hard soils, it may lead to wrong results for soft and loose soils [19]. In recent years, some studies have been carried out in fields such as Soil-StructureInteraction (SSI) [20] and Structure-FoundationSoil Interaction (SFSI) [21,22]. Camata et al. [23] determined that the boundary conditions and properties of the soil on the structural behavior of a tower built in Italy had great importance on the seismic behavior of the structure. Haciefendioğlu [24] determined that stress and displacements decreased due to the frozen ground temperature. Pitilakis and Karatzetzou [25] investigated the dynamic rigidity of the monumental wall foundation, considering the interaction of SFSI and determined that the structural behavior significantly changed with the SFSI effect. Casolo et al. [19] found that the soil of a bell tower had a significant effect on the second mode's characteristics and the structure's damage situation. Silva et al. [26] investigated the effect of SFSI on Carmine tower's seismic performance, which is the tallest tower of Naples and determined that the SFSI should be considered in regions with insufficient lateral rigidity. Hökelekli and Al-Helwani [20] stated that SSI significantly affected the damage distribution and rate of masonry structures. Ismail et al. [27] determined that the soil medium was effective on RC structures' behavior. Fathi et al. [28] investigated the effect of SSI on the out of plane behavior of walls and found that the displacements and acceleration demands significantly changed. Scarfone et al. [29] determined that the soft soil layer behaves like a natural damper.

In this study, the stone masonry minaret of the historical Ibrahim Celebi Mosque (1549) is investigated by considering the SSI effect. Three FE models are created for the nonlinear analyses. The first model's base is restrained with the fixed support (F-S). The second and third models are assumed to locate on soft soil (S-SSI) and hard soil (H-SSI), respectively. The Concrete Damage Plasticity (CDP) model is used for the failure 
behavior of the minaret. Nonlinear time-history analyses are performed using the 1999 Kocaeli earthquake records $(\mathrm{Mw}=7.4)$. Finally, the soil medium's effect on the damage distribution and rates, principal stresses, and displacements are determined.

\section{Geometrical and material properties}

Ibrahim Celebi Mosque was built by Ibrahim Celebi in 1549 during the Ottoman period and repaired in 1881. Ibrahim Celebi Mosque has a square plan and a single dome. The minaret, located on the left side of the mosque entrance, consists of a boot, transition segment, cylindrical body, balcony, upper part, spire, and end ornament parts. The boot section was constructed using cut stone, ashlar, and partition tiles. The transition segment, body, balcony, and upper part of the minaret body parts were built with the cut stone. The inner part of the spire is covered with wood and the outer part with lead coating. Inside the minaret, a core-bodied staircase is located. The average height of the stairs is $25 \mathrm{~cm}$. In many parts of the minaret, steel clamps and dowels were used to connect elements in horizontal and vertical directions. During the field studies, damages were observed on the surfaces of the stones in the transition segment, upper and body parts of the minaret. In addition, there are local repairs in some parts of the minaret. The mosque and minaret are shown in Fig. 1, and the geometrical properties are shown in Fig. 2. The total height of the minaret is $30.08 \mathrm{~m}$. The boot dimensions of the minaret are $2.82 \times 2.82 \mathrm{~m}$.

\section{FE modeling and analysis}

\subsection{Initial FE model and frequency analysis}

At the beginning of numerical studies, a building survey is performed in situ. The obtained drawings are transformed into a three-dimensional solid model in the AUTOCAD software. Solid model of minaret is transferred to the ABAQUS/CAE software [30]. It is a FE software that enables detailed analysis by providing the opportunity to create realistic models. Thanks to its different material models and FE types, it offers the opportunity to analyze linear and non-linear projects that are difficult to solve. The frequency analyses are performed to determine the FE models' optimum mesh size, and the convergence graph is obtained (Fig. 3).

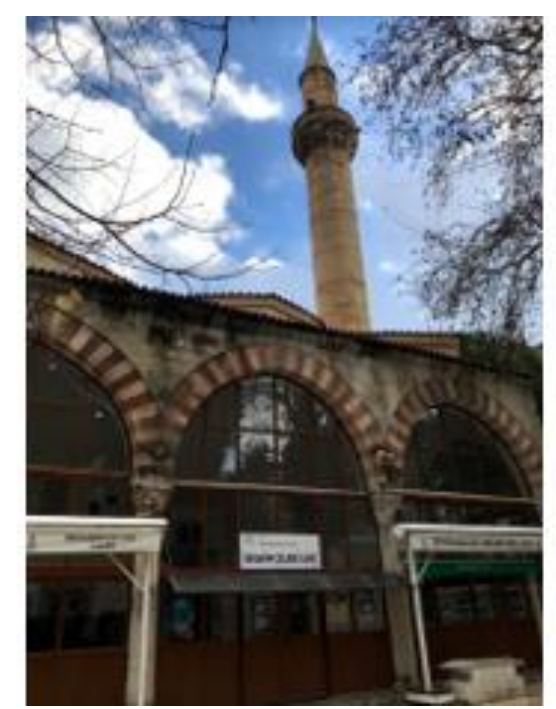

(a)

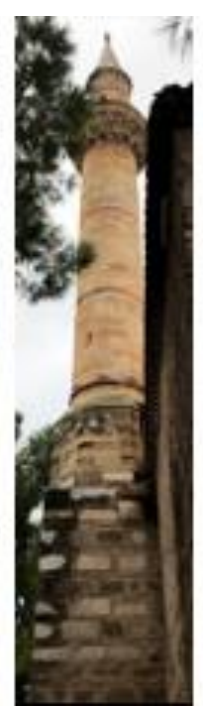

Fig. 1 Ibrahim Celebi Mosque and minaret

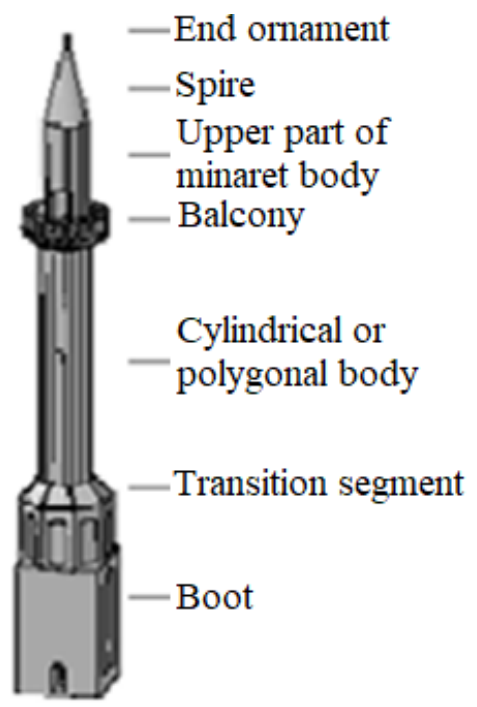

(b) 


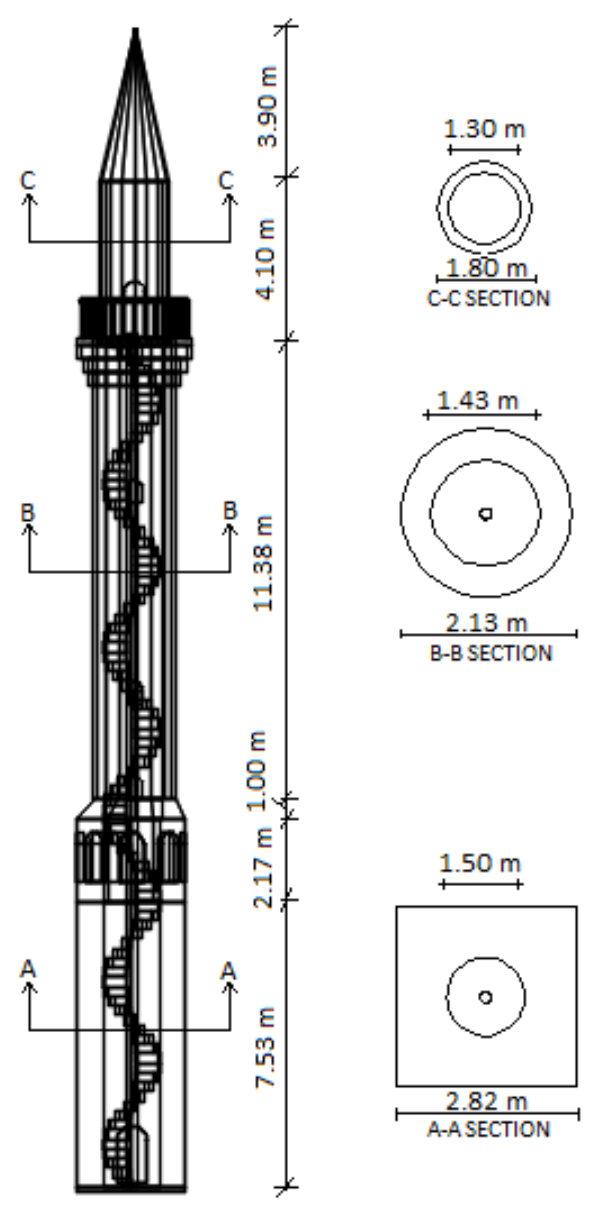

Fig. 2 Geometric properties of the minaret

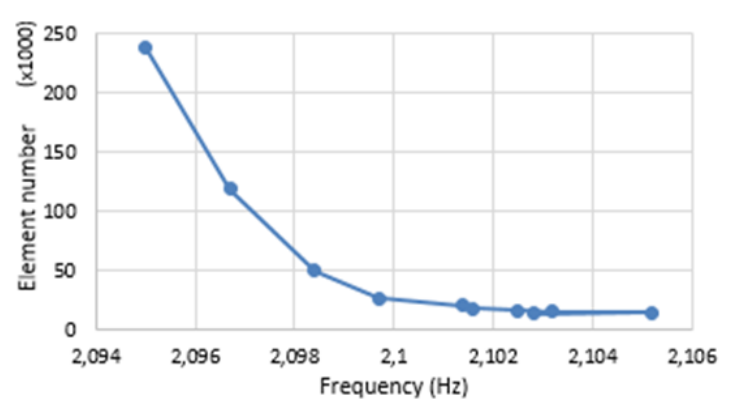

Fig. 3 Convergence graph

According to the convergence graph, the optimum mesh size is determined as $30 \mathrm{~cm}$. In this way, 82,789 nodes and 50,274 quadratic tetrahedral elements (C3D10) are used in the minaret's FE model. FE section views, initial support conditions and meshing of the minaret are presented in Fig. 4. Since the stone and mortar used in all parts of the minaret are similar and the macro modeling method is preferred in numerical modeling, a uniform material has been defined. Material parameters of the initial FE model of the minaret are taken from [31] and presented in Table 1. Depending on the size and importance of the structural system, detailed micro, simplified micro and macro modeling approaches can be used for numerical modeling of masonry structures [32]. The macro modeling approach considers masonry as a continuous homogeneous material with isotropic or anisotropic behavior. When considered the size and complexity of masonry structures, the FE macro modeling approach is an effective tool that can be applied to large-scale calculations. The method also harmonizes with damage investigations [33-35]. In the macro modeling, the structural element subjected to the homogenization process is considered as a composite material. With the homogenization technique, masonry wall consisted of brick-stone and mortar are modeled as a single material. This situation also provides a great gain in terms of time during the modeling and analysis stages

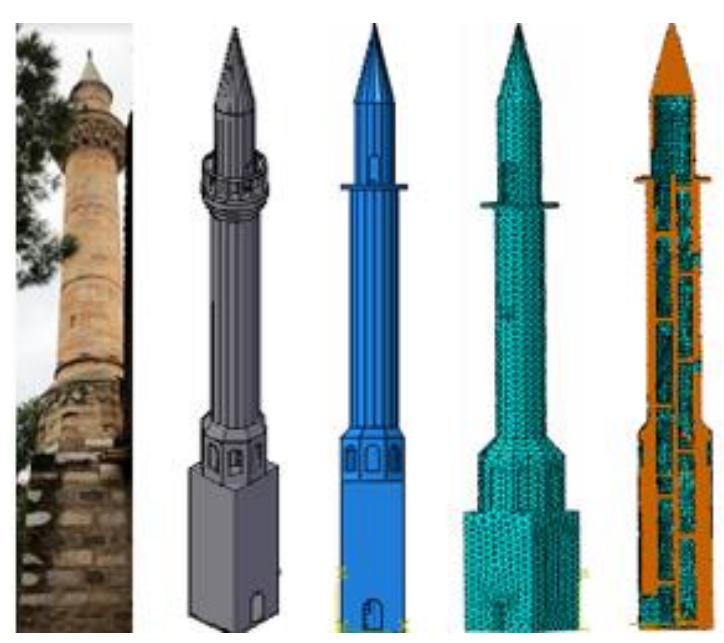

Fig. 4 Solid and FE models of the minaret

Table 1. Initial mechanical properties of the minaret [31]

\begin{tabular}{lc}
\hline Mechanical Parameter & Masonry Wall \\
\hline Initial Young Modulus $(\mathrm{MPa})$ & 8856 \\
Weight per unit volume $\left(\mathrm{kg} / \mathrm{m}^{3}\right)$ & 2300 \\
Poisson ratio & 0.24 \\
\hline
\end{tabular}




\subsection{Operational modal analysis}

OMA method is often used to obtain the structure's experimental dynamic properties [3,5-7,9,10]. In the OMA method, the natural and environmental vibrations affect the structure, and then accelerations occurred on the structure are collected. 8 accelerometers were placed in the $\mathrm{X}$ and $\mathrm{Y}$ directions to the points on minaret determined as a result of initial FE analysis (Fig. 5). Acceleration records were processed with the ARTeMIS software [36], and the dynamic characteristics of the minaret were obtained. EFDD and Stochastic Subspace Identification techniques were used to obtain dynamic characteristics. Figs. $6(\mathrm{a}$ and $\mathrm{b})$ presents the spectral density matrix obtained from the EFDD and Stochastic Subspace Identification stabilization diagrams, respectively. Natural frequencies and damping ratios obtained by
EFDD and Stochastic Subspace Identification techniques are shown in Table 2. Natural frequencies and mode shapes obtained from the initial FE model and OMA are presented in Fig. 7. Natural frequency values obtained from the initial FE model and OMA method and the differences are presented in Table 3.

\subsection{Model updating}

As shown in Table 3, there are significant differences between the two methods in terms of natural frequencies. To reduce these differences, the young's modulus was parametrically changed $[7,13]$. As a result of the parametric studies, the initial young's modulus was reduced from 8856 MPa to $4975 \mathrm{MPa}$. Thus, differences between these methods are considerably reduced and presented in Table 4.

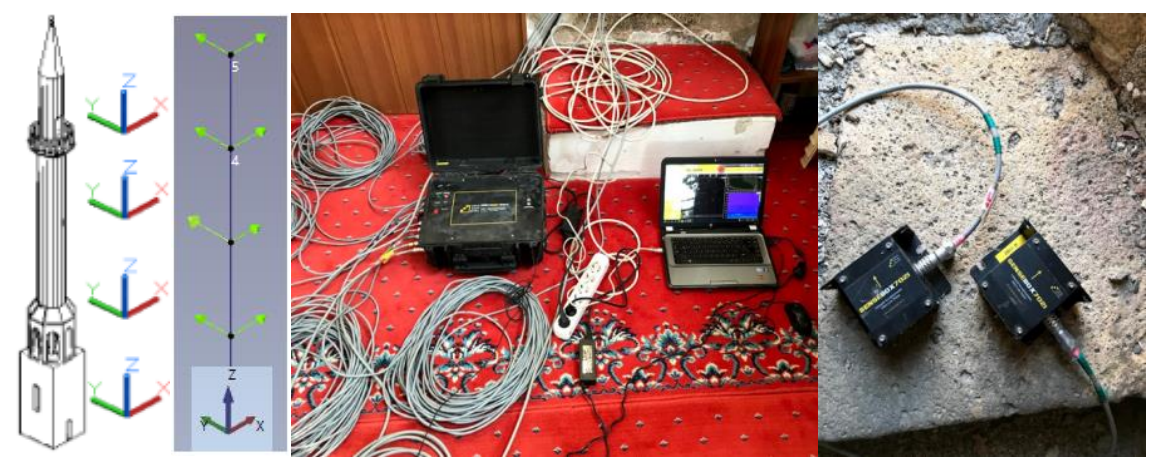

Fig. 5 Data acquisition device and location of accelerometers

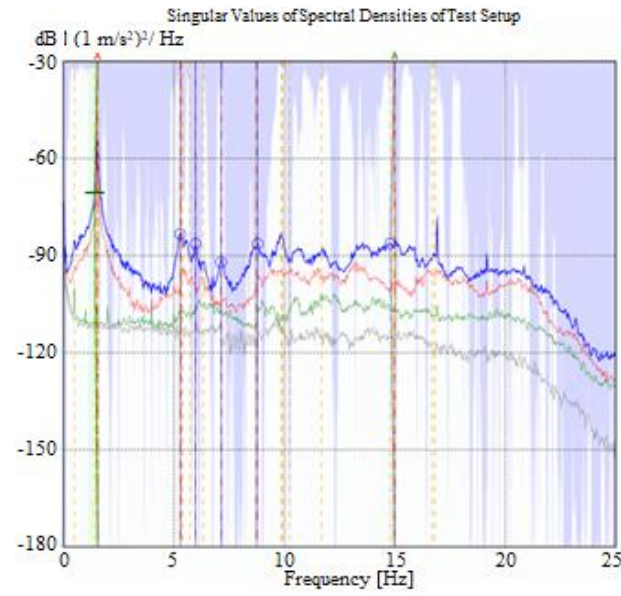

(a)

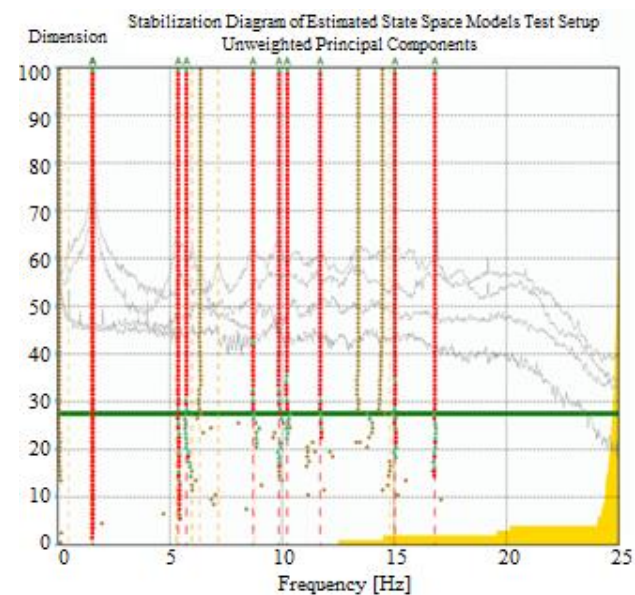

(b)

Fig. 6. EFDD and Stochastic Subspace Identification results: (a) Singular values of spectral densities matrices obtained from the EFDD method, (b) Stabilization diagram of estimated state-space models 


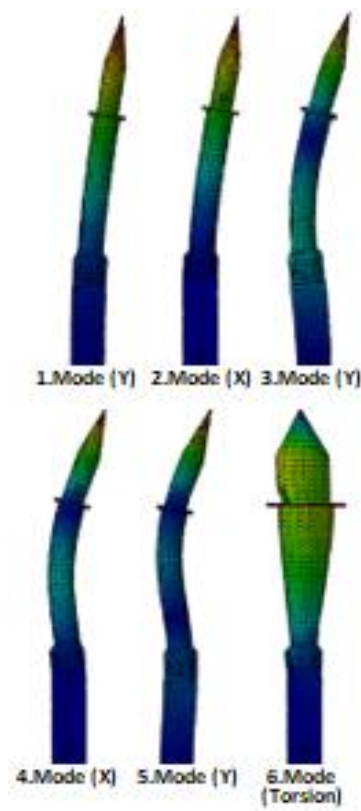

(a)

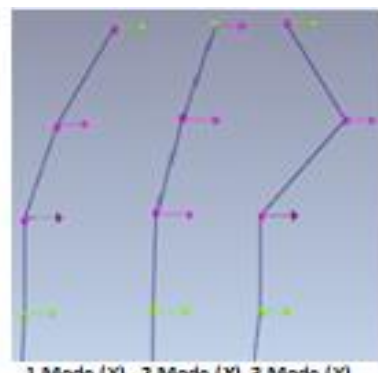

1.Mode (Y) 2.Mode ( $\mathrm{X}$ ) 3.Mode (Y)

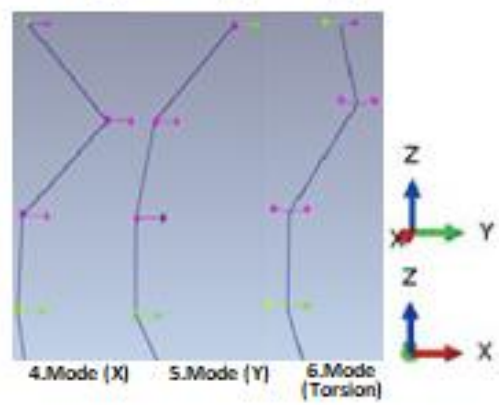

(b)

Fig. 7 Comparison of mode shapes: (a) FE analysis, (b) OMA analysis

Table 2. Natural frequencies and damping ratios obtained by OMA method

\begin{tabular}{|c|c|c|c|}
\hline \multirow[b]{2}{*}{ Mode } & \multicolumn{2}{|c|}{$\begin{array}{l}\text { Natural Frequencies } \\
\text { obtained with OMA }\end{array}$} & \multirow{2}{*}{$\begin{array}{c}\text { Damping } \\
\text { Ratios (\%) }\end{array}$} \\
\hline & $\mathrm{SSI}^{*}(\mathrm{~Hz})$ & EFDD (Hz) & \\
\hline 1 & 1.567 & 1.563 & 0.999 \\
\hline 2 & 1.765 & 1.576 & 1.078 \\
\hline 3 & 5.563 & 6.050 & 3.265 \\
\hline 4 & 8.712 & 8.965 & 3.129 \\
\hline 5 & 9.805 & 9.012 & 4.004 \\
\hline 6 & 12.011 & 12.240 & 2.483 \\
\hline
\end{tabular}

*SSI: Stochastic Subspace Identification

Table 3. Comparison of natural frequencies obtained from the initial FE model and OMA

\begin{tabular}{cccc}
\hline Mode & $\begin{array}{c}\text { FE } \\
\text { analysis } \\
(\mathrm{Hz})\end{array}$ & $\begin{array}{c}\text { Difference } \\
\text { between } \\
\text { FE-EFDD } \\
(\%)\end{array}$ & $\begin{array}{c}\text { Difference } \\
\text { between } \\
\text { FE-SSI* } \\
(\%)\end{array}$ \\
\hline 1 & 2.0984 & 34.3 & 34 \\
\hline 2 & 2.6079 & 65.5 & 47.8 \\
\hline 3 & 7.9134 & 30.8 & 42.3 \\
\hline 4 & 12.657 & 41.2 & 45.3 \\
\hline 5 & 17.189 & 90.7 & 75.3 \\
\hline 6 & 19.325 & 57.9 & 60.9 \\
\hline
\end{tabular}

*SSI: Stochastic Subspace Identification
Table 4. Comparison of natural frequencies of updated FE model and OMA

\begin{tabular}{cccc}
\hline Mode & $\begin{array}{c}\text { FE } \\
\text { analysis } \\
(\mathrm{Hz})\end{array}$ & $\begin{array}{c}\text { Difference } \\
\text { between } \\
\text { FE-EFDD } \\
(\%)\end{array}$ & $\begin{array}{c}\text { Difference } \\
\text { between } \\
\text { FE-SSI* } \\
(\%)\end{array}$ \\
\hline 1 & 1.5728 & 0.6 & 0.3 \\
\hline 2 & 1.6705 & 6 & 5 \\
\hline 3 & 5.9312 & 2 & 7 \\
\hline 4 & 9.9433 & 11 & 14 \\
\hline 5 & 9.7329 & 8 & 0.7 \\
\hline 6 & 13.3416 & 9 & 11 \\
\hline
\end{tabular}

*SSI: Stochastic Subspace Identification

\subsection{Concrete damage plasticity model}

The Concrete Damage Plasticity (CDP) material model is used for the stone masonry of the minaret in nonlinear time history analysis. The CDP material model consists of concrete's plastic behaviour, compression behaviour and tension behaviour. In this model, the uniaxial tension and crush behaviours are characterized by damaged plasticity. The degradation of the elastic stiffness is characterized by two damage variables, denoted as $d_{t}$ and $d_{c}$ in tension and compression, respectively, which are increasing functions of the equivalent plastic strains: their values range between zero and 
one, representing a zero-damage state and complete damage state. Although the CDP model was developed to describe concrete's plastic behavior, it could also be used in masonry structures [37,38]. Bayraktar et al. [39] investigated the damage rate and distribution in the minaret of the historical Ulu Mosque in Diyarbakır. Using the CDP material model, Nohutcu [18] identified the damage distribution of a historic masonry minaret and observed that the damage concentrated in the minaret's transition segment. Hökelekli et al. [13] performed the linear and nonlinear damage analyses using the CDP material model in a historical minaret. The CDP model is based on 2 main failure mechanisms. These are cracking of concrete due to tensile stress and crushing due to compressive stress. The stress-strain relationships of concrete subjected to compressive and tensile stresses are shown in Fig. 8

If the initial stiffness of the material is $E_{o}$, the stress-strain relationships under uniaxial compressive and tensile stresses are defined by

$$
\begin{aligned}
& \sigma_{t}=\left(1-d_{t}\right) E_{0}\left(\varepsilon_{t}-\varepsilon_{t}^{-p l}\right) \\
& \sigma_{c}=\left(1-d_{c}\right) E_{0}\left(\varepsilon_{c}-\varepsilon_{c}^{-p l}\right)
\end{aligned}
$$

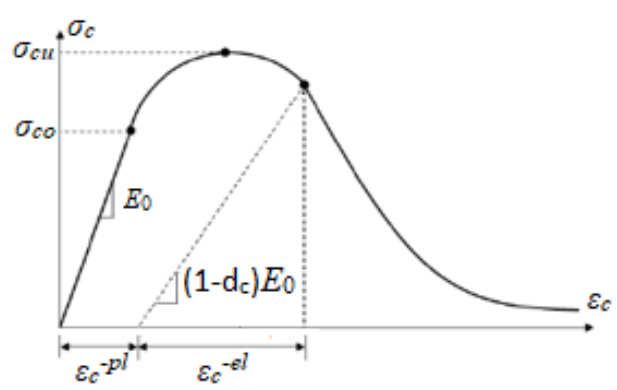

(a) where $E_{0}$ is the initial modulus of elasticity, $\sigma_{c}\left(\sigma_{t}\right)$ is the uniaxial compressive (tensile) stress, $\varepsilon_{c}\left(\varepsilon_{t}\right)$ is the total strain in compressive (tensile) condition, $\varepsilon_{c}^{-p l}\left(\varepsilon_{t}^{-p l}\right)$ is the equivalent plastic strain in conditions, and $\mathrm{d}_{\mathrm{c}}$ and $\mathrm{d}_{\mathrm{t}}$ are damage parameters for compressive and tensile stresses.

To model the masonry's nonlinear behavior, a CDP material model that exhibits the softening under the compression and tension stresses is used. The CDP material properties are shown in Table 5, and the stress-strain, and damage parameters are shown in Table 6 [40].

In this study, the soil-structure interaction on a historical minaret's structural behavior is investigated. For this purpose, three models with fixed support (F-S), hard soil (H-SSI), and soft soil (S-SSI) in the base are created. These models are as follows.

Table 5. Material parameters for masonry in the CDP model [40]

\begin{tabular}{ccccc}
\hline Dilation angle & Eccentricity & fbofco & $\mathrm{K}$ & Viscosity \\
\hline $10^{0}$ & 0.1 & 1.166 & 0.666 & 0.001 \\
\hline
\end{tabular}

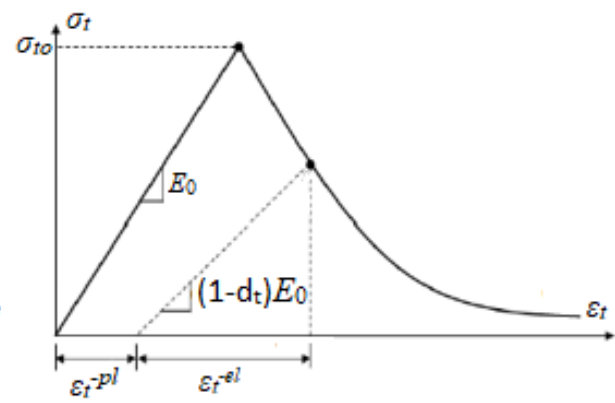

(b)

Fig. 8 Behaviour of concrete under axial compressive (a) and tension (b) strength [23]

\begin{tabular}{|c|c|c|c|}
\hline \multicolumn{2}{|c|}{ Tension behaviour } & \multicolumn{2}{|c|}{ Compression behaviour } \\
\hline Yield stress & Cracking strain & Yield stress & Inelastic strain \\
\hline 0.2 & 0 & 2 & 0 \\
\hline 0.02 & 0.0025 & 2 & 0.0015 \\
\hline 0.02 & 0.01 & 0.2 & 0.005 \\
\hline \multicolumn{2}{|c|}{ Tension } & \multicolumn{2}{|c|}{ Compression } \\
\hline Damage & Cracking strain & Damage & Inelastic strain \\
\hline 0 & 0 & 0 & 0 \\
\hline 0.95 & 0.005 & 0.95 & 0.005 \\
\hline
\end{tabular}

Table 6. Uniaxial stress-strain and scalar damage values utilized in the CDP model for masonry [40] 


\subsection{Fixed support model}

Firstly, a survey study is performed to determine the minaret's geometric properties. 3D solid model, which is created in the AutoCAD software, is transferred to the ABAQUS/CAE software for FE analyses. Solid and FE models of the minaret are presented in Fig. 4. Then, the minaret's soil medium is neglected, and the fixed supports in the minaret base are modeled. This model is called the F-S. 82,789 nodes and 50,274 quadratic tetrahedral elements of type C3D10 are used for each model. The C3D10 element is a general-purpose tetrahedral element (4 integration points), is used for the minaret's FE modeling, as shown in Fig. 9(a).

\subsection{Soil-structure interaction}

In FE analyses, the structures are generally modeled with fixed supports, and the soil medium is neglected. Although this assumption gives reasonable results for hard soils, it may cause some errors, especially in soft and loose soils. Some studies have been performed on SSI and SFSI in recent years [20-22]. SSI is generally performed with 3 different methods. These are discrete mathematical models. These models are the model where the soil is defined by springs and dampers, and the FE models where the structure and soil are combined. In this study, the FE model is created by considering the structure and soil together. To determine the effect of the soil's mechanical properties on the structural behavior, soil models having two different mechanical properties occur. These soil types' material properties and Rayleigh damping coefficients $\left(\alpha_{r}\right.$ and $\left.\beta_{r}\right)$ are shown in Table 7 [41]. Material damping ratios were calculated by

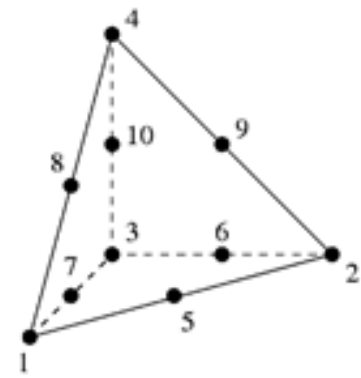

(a)

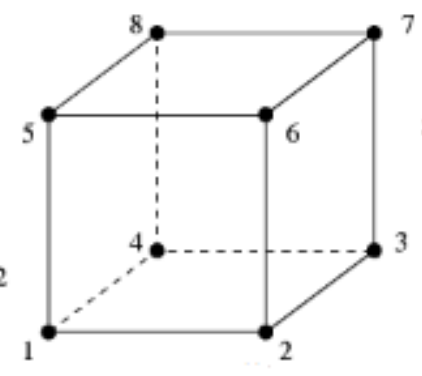

(b)

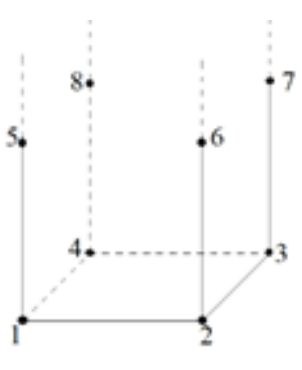

(c)
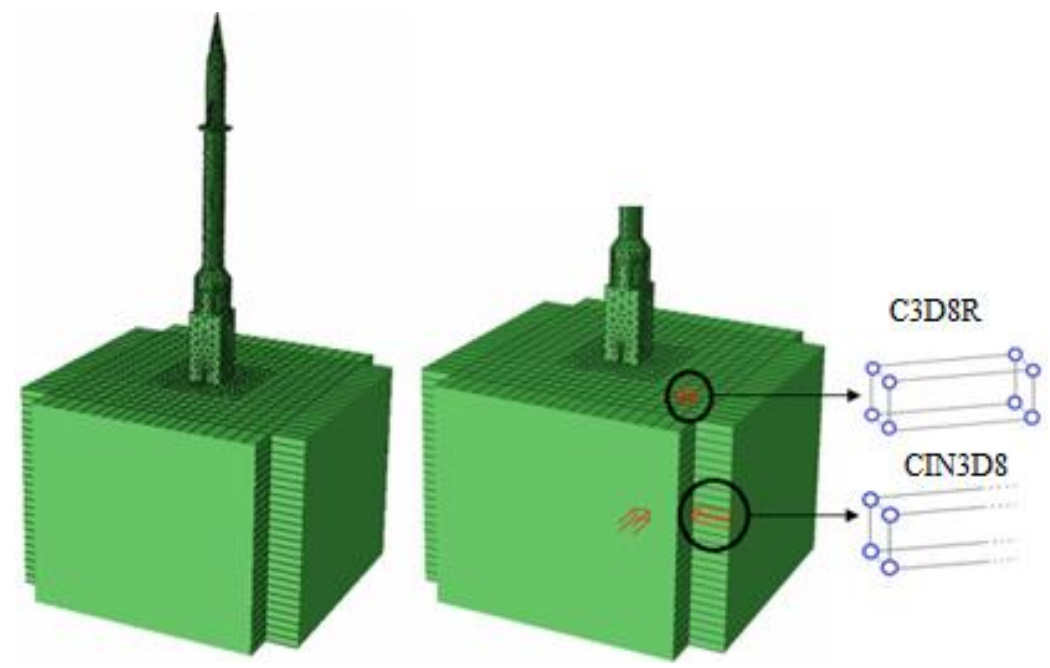

(d)

Fig. 9 SSI model, infinite and finite element types 
Table 7. Linear material properties of soil medium [41]

\begin{tabular}{ccccccccc}
\hline Soil & $\begin{array}{c}\text { Density } \\
\left(\mathrm{kg} / \mathrm{m}^{3}\right)\end{array}$ & $\begin{array}{c}\text { Modulus of } \\
\text { elasticity } \\
\left(\mathrm{N} / \mathrm{m}^{2}\right)\end{array}$ & $\begin{array}{c}\text { Poisson's } \\
\text { ratio }(\mathrm{u})\end{array}$ & $\begin{array}{c}\text { Shear } \\
\text { modules } \\
\left(\mathrm{N} / \mathrm{m}^{2}\right)\end{array}$ & $\begin{array}{c}\text { P wave } \\
\text { velocity } \\
\mathrm{V}_{\mathrm{s}}(\mathrm{m} / \mathrm{s})\end{array}$ & $\begin{array}{c}\text { Shear wave } \\
\text { velocity } \mathrm{V}_{\mathrm{s}} \\
(\mathrm{m} / \mathrm{s})\end{array}$ & $\alpha_{\mathrm{r}}$ & $\beta_{\mathrm{r}}$ \\
\hline Hard & 2.064 & $5.68 \mathrm{E}+09$ & 0.30 & $2.10 \mathrm{E}+09$ & 2.082 & 1 & 3.920 & 0.00047 \\
Soft & 1.864 & $3.61 \mathrm{E}+08$ & 0.35 & $1.38 \mathrm{E}+08$ & 505.5 & 270 & 1.059 & 0.00176 \\
\hline
\end{tabular}

$\alpha_{r}=\xi \frac{2 \omega_{i} \omega_{j}}{\omega_{i}+\omega_{j}}, \beta_{r}=\xi \frac{2}{\omega_{i}+\omega_{j}}$

where $\omega_{i}$ and $\omega_{j}$ denote the angular natural frequencies for the $i^{\text {th }}$ and $j^{\text {th }}$ modes and $\xi$ is the structural damping ratio.

Seismic effects change depending on the depth of the soil. Maheswari et al. [42] observed volumetric expansion and contraction in the area within $30 \mathrm{~m}$ of the soil during the earthquake and suggested that the depth should be at least $30 \mathrm{~m}$ in the model. Therefore, the soil depth is assumed 30 $\mathrm{m}$ in the seismic analyses.

In FE modelling, the C3D8R element is the hexagonal type with 8 nodes and reduced integration, is used for the soil medium, as shown in Fig. 9(b). In the FE method, the soil boundaries' modeling is an significant factor [21]. It is recommended to expand the soil medium until the region where the soil's effect on the structure is minimal. This situation increases the number of meshes and boundary conditions, and it significantly increases the solution time of nonlinear analyses. In dynamic analysis, improper soil boundary conditions may cause artificial dynamic effects. For this reason, infinite elements are used at the boundaries of soil models. The "CIN3D8" infinite element is 8-node linear and one-way infinite, is defined for the elements in the soil boundaries, as shown in Figs. 9(c and d). The minaret's FE model has 103,881 nodal points. 82,789 of these nodal points are used in the minarets, and 21,092 points are used in the soil. A total of 65,582 elements are used, including 5,200 elements of C3D8R, 1,440 of CIN3D8, and 58,942 of C3D10. Finite, infinite elements and FE models with SSI are presented in Fig. 9.

\subsection{The strong ground motions}

Nonlinear time-history analyses are performed with ABAQUS/CAE software. In S-SSI and H-SSI models, the earthquake records are applied at the base of the model. Acceleration records of the Kocaeli earthquake with $\mathrm{Mw}=7.4$ magnitude, dated August 19, 1999, are used in the minaret's seismic analyses (in Fig. 10(a)). The acceleration component with a maximum value of $373.7 \mathrm{~cm} / \mathrm{s}^{2}$ is applied in the minaret's horizontal $(x)$ direction. Many researchers have used the effective portion of acceleration records instead of a full record [20,33,43-47]. The effective portion, which is between 7-19 seconds, has been obtained by using Housner and Arias intensity methods with DEEPSOIL software [48] as shown in Fig. 10 (a and $b$ ).

\section{Results and discussion}

As a result of the analyses, the dynamical parameters, displacements, principal stress contours, damage ratios, and distribution are obtained. The initial material properties are calibrated by using experimental and numerical methods together to realistically determine the performance of the minaret. The mode shapes obtained in both methods are quite similar. The post-calibration model's initial young's modulus is reduced from $8856 \mathrm{MPa}$ to $4975 \mathrm{MPa}$. The difference of $34 \%$ between the natural frequency values of the methods in the $1^{\text {st }}$ mode decreases to $0.6 \%$ after the calibration.

The displacements that occurred throughout the height of these models are presented in Fig. 11. The displacement variations for the top point of the models are shown in Fig. 12(a). The interstory drifts between the top and the base of the models are shown in Fig. 12(b). 


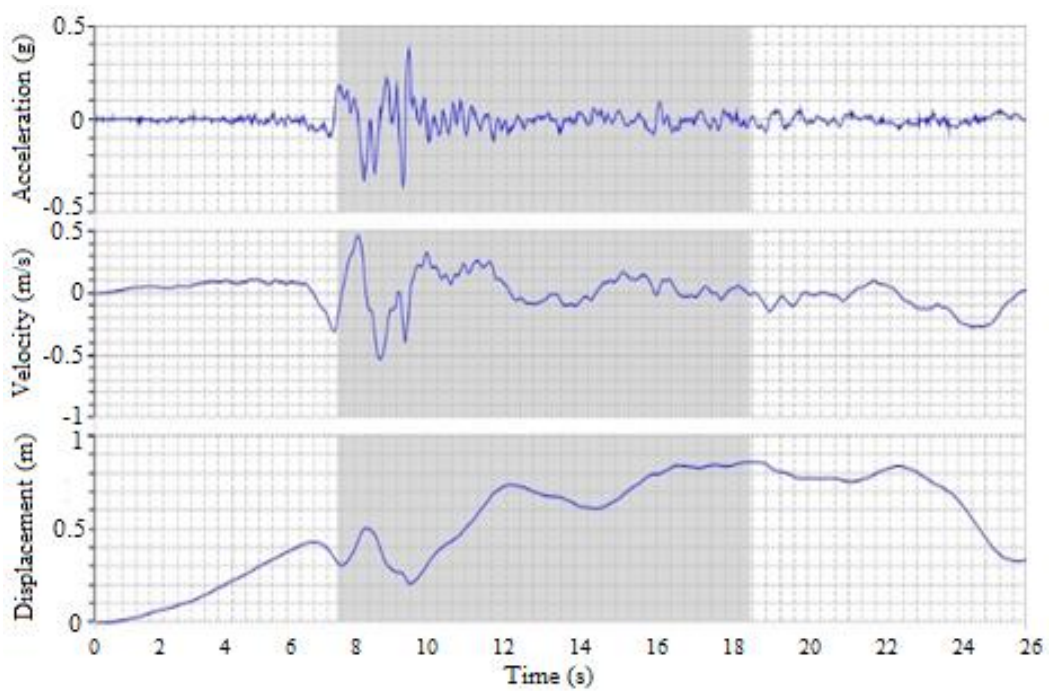

(a) Effective portion of the Kocaeli earthquake's acceleration records

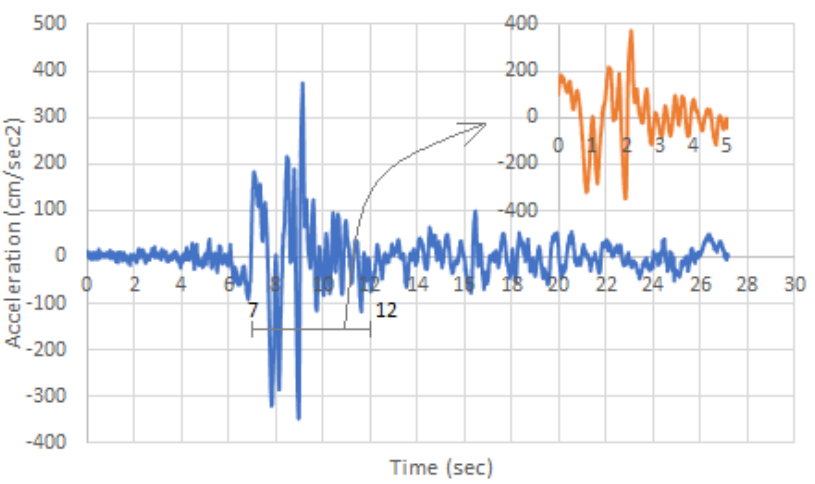

(b) All and effective acceleration records of the Kocaeli earthquake

Fig. 10. Kocaeli earthquake's acceleration records

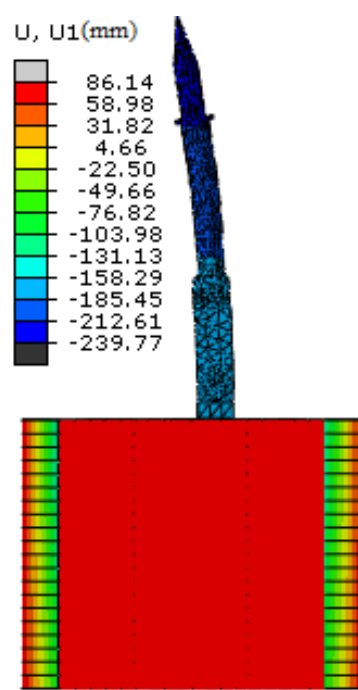

(a) H-SSI

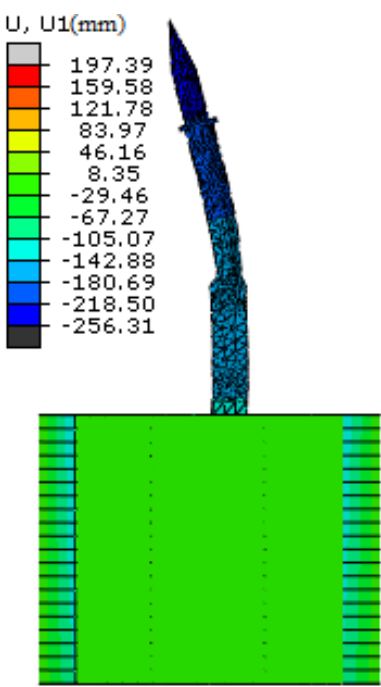

(b) S-SSI

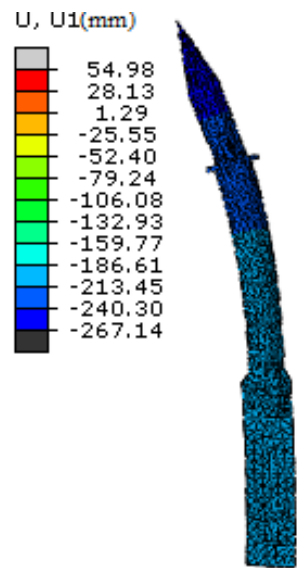

(c) F-S

Fig. 11. Displacements contours for each model 


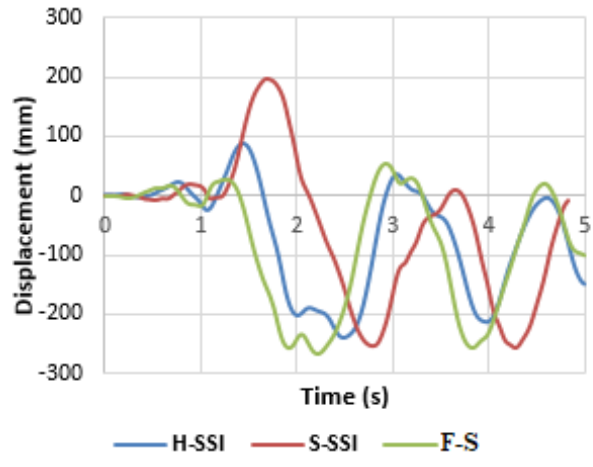

(a)

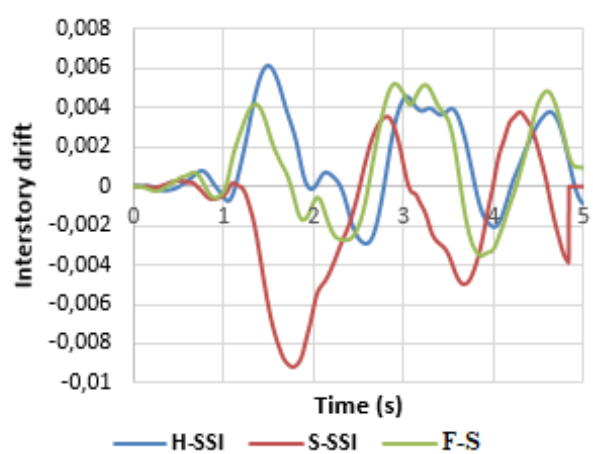

(b)

Fig. 12 Displacements and interstory drifts

The maximum displacements for the top of the models are $239.77 \mathrm{~mm}, 256.31 \mathrm{~mm}$, and $267.14 \mathrm{~mm}$ for H-SSI, S-SSI, and F-S models, respectively. The interstory drifts are $0.00608,0.00921$, and 0.00515 for the H-SSI, S-SSI, and F-S models, respectively. S-SSI model moves towards the opposite direction of the other models, as shown in Fig. 12(a). The highest interstory drift occurs in the S-SSI model.

Maximum and minimum principal stresses are shown in Figs. 13 and 14. The variation of principal stresses is shown in Fig. 15. Maximum principal tensile stresses are $3.23 \mathrm{MPa}, 3.66 \mathrm{MPa}$, and 3.73 $\mathrm{MPa}$ for H-SSI, S-SSI and F-S models, respectively. While the highest tensile stress occurs in the F-S model, the lowest tensile stress occurs in the H-SSI model. Critical tensile stresses are concentrated in the transition segments of all models, as shown in Fig. 13. Minimum principal stresses are -6.29 $\mathrm{MPa},-5.40 \mathrm{MPa}$ and -8.31 $\mathrm{MPa}$ for H-SSI, S-SSI, and F-S models, respectively. The highest compressive stress occurs in F-S, and the lowest compressive stress occurs in the S-SSI model. It is observed that the compressive stresses are concentrated in the transition segment in all models.

The plastic strains formed due to compressive and tensile stresses are presented in Figs. 16 and 17, respectively. In Figs. 16 and 17, grey and red colors represent the highest values, and the blue color represents the lowest values. Fig. 16 shows the plastic strains (PEEQ) that occurred by the compressive stress. Accordingly, $0.096 \%$ of the SSSI model's total elements, $0.071 \%$ in $\mathrm{H}-\mathrm{SSI}$, and $0.065 \%$ in F-S exceed the limit plastic strain
(0.0035) in compression. Plastic strains (PEEQT) formed with tensile stresses are presented in Fig. 17. Accordingly, $24.18 \%$ of F-S's total elements, $11.78 \%$ in H-SSI, and $10.15 \%$ in S-SSI have exceeded the limit plastic strain (0.0002) in tension.

Damage ratios and distributions for each model are presented in Figs. 18 and 19. The compressive $\left(d_{c}\right)$ and tensile $\left(d_{t}\right)$ damage parameters are shown in Figs. 18 and 19, respectively. The color portions of the damage parameter are also stated: blue color to slightly damage, red color is associated with heavy damage. Heavily compressive damages have occurred in 8 elements of the F-S model, 8 of the HSSI model, and 6 of the S-SSI model, as shown in Fig. 18. Compressive damage ratios in the models are $0.028 \%$ of H-SSI and F-S models' total elements and $0.021 \%$ in S-SSI models. Compressive damages occur in the transition segment of each model. Maximum tensile damages have observed in the F-S model. Heavily tensile damages have occurred in 4308 elements of the F-S model, 1300 of the H-SSI model, and 1059 of the S-SSI model, as shown in Fig. 19. Accordingly, the tensile damage ratios are $15.29 \%$ of the F-S model's total elements, $4.61 \%$ in the H-SSI model and $3.76 \%$ in the S-SSI model. In all models, it is determined that the tensile damages concentrate on the transition segment and the cylindrical body of the minaret in the form of a bracelet. However, it is observed that the tensile damages in the F-S model spread to a more extensive region than the others. Under compressive and tensile stresses, the number of heavily damaged elements is shown in Fig. 20. 


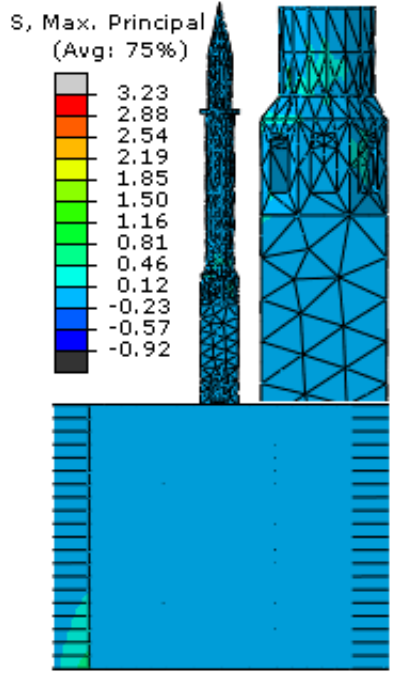

(a) H-SSI

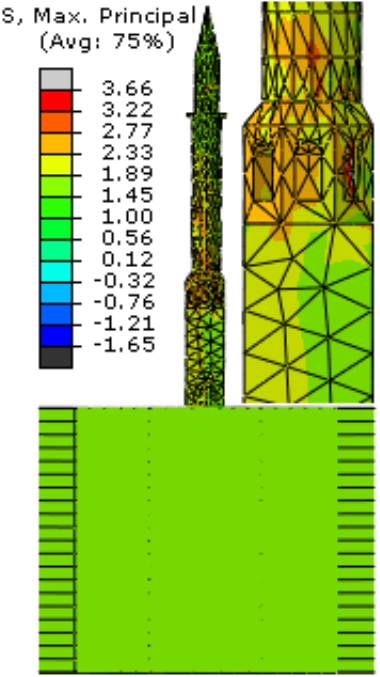

(b) S-SSI

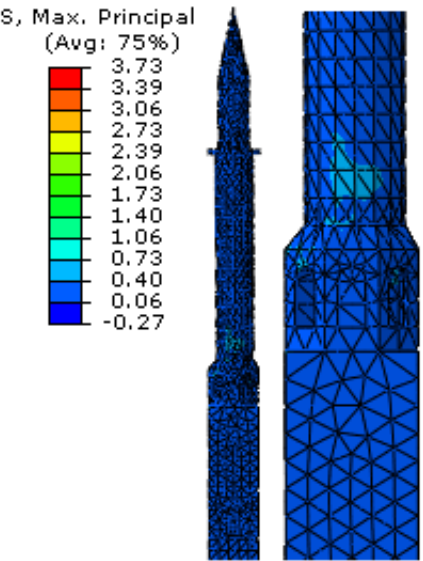

(c) F-S

Fig. 13. Maximum principal stress (MPa) contours

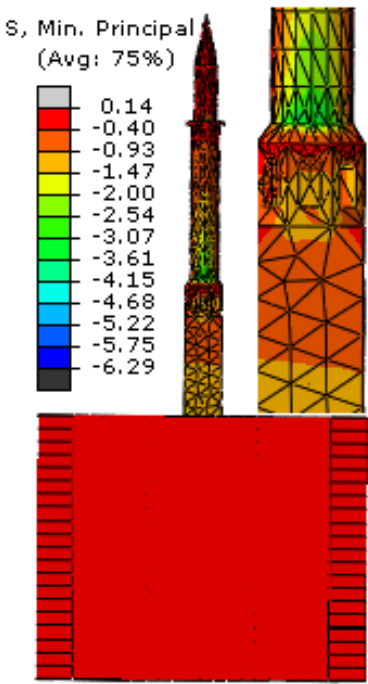

(a) H-SSI

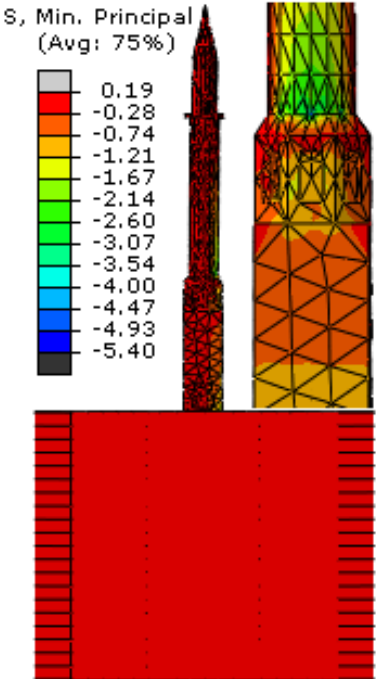

(b) S-SSI

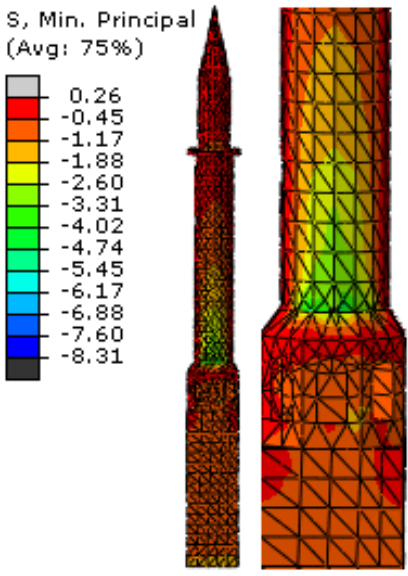

(c) F-S

Fig. 14. Minimum principal stress (MPa) contours
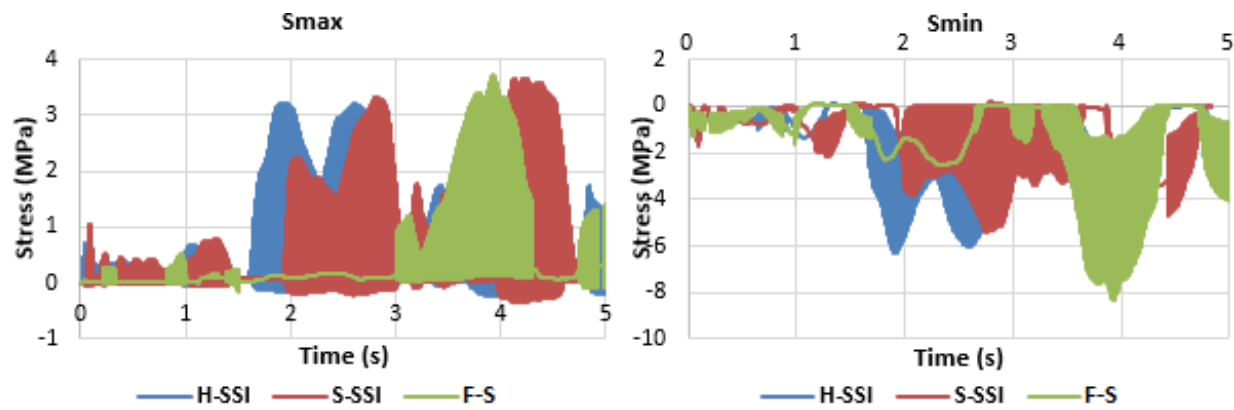

Fig. 15. Time-dependent change of maximum and minimum principal stresses 


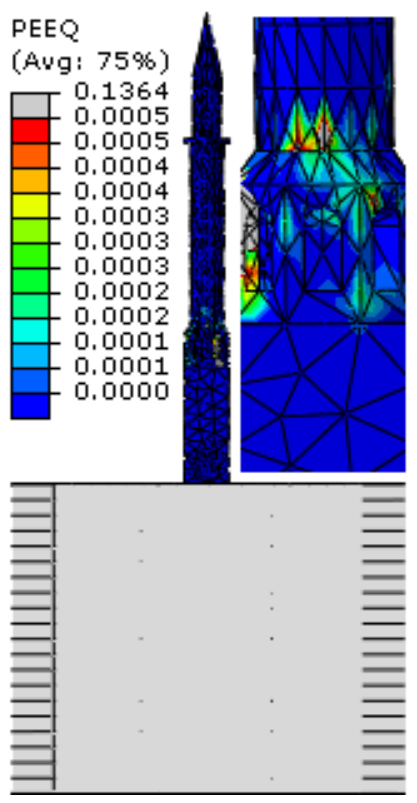

(a) H-SSI

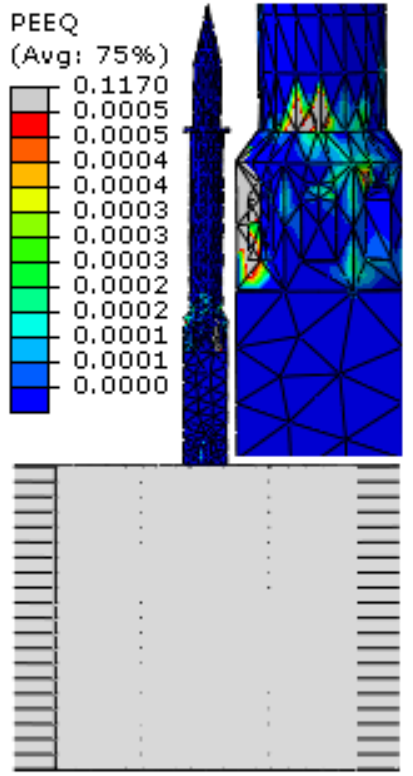

(b) S-SSI
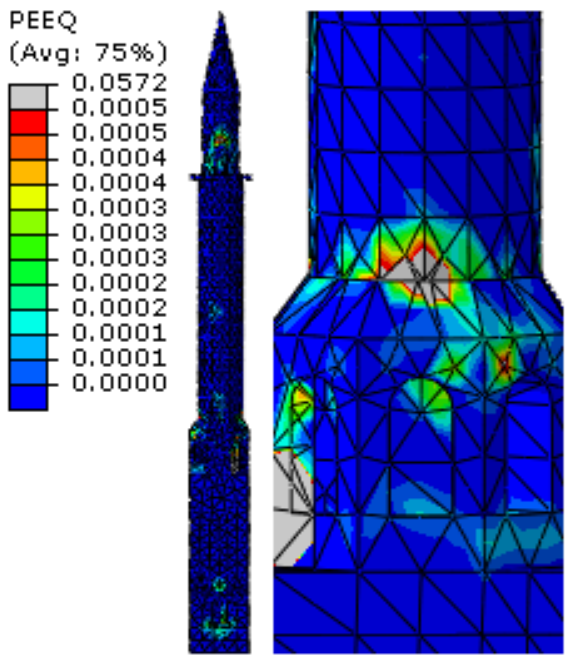

(c) F-S

Fig. 16. Plastic strains formed with compressive stresses

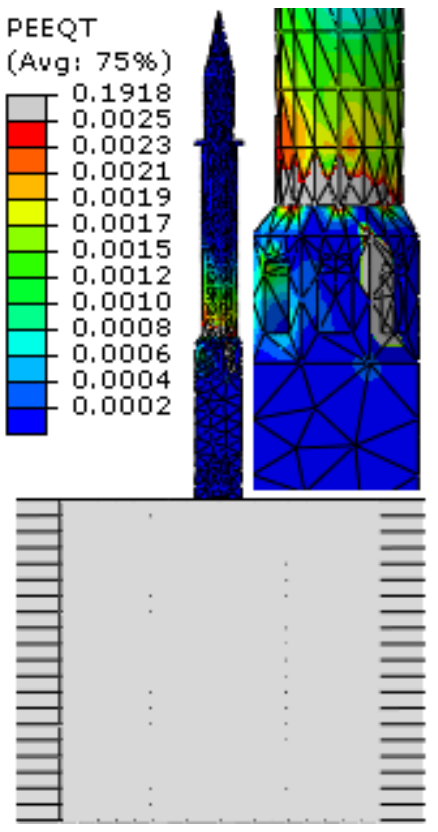

(a) H-SSI

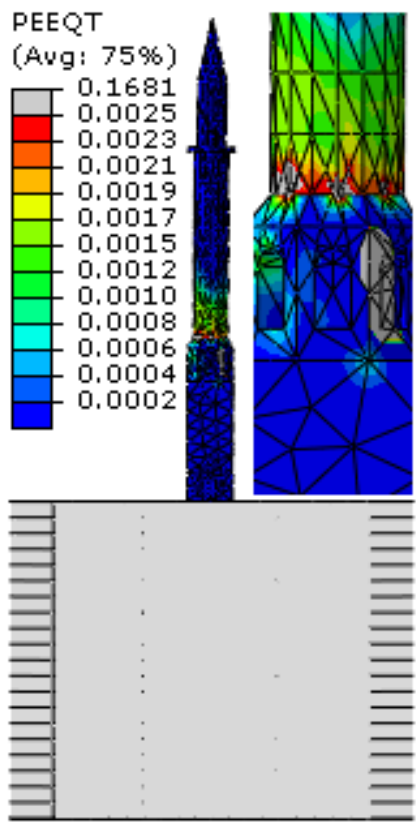

(b) S-SSI

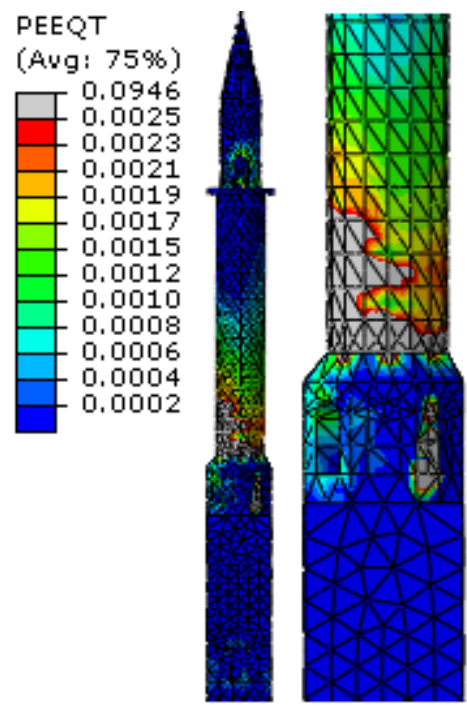

(c) F-S

Fig. 17. Plastic strains formed with tensile stresses 


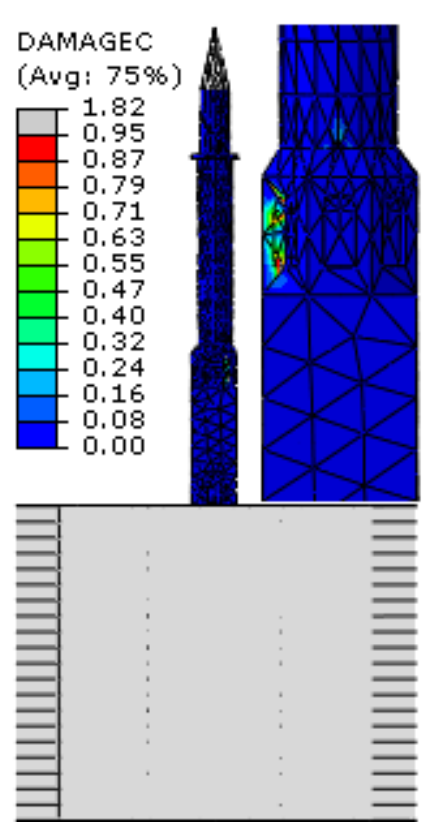

(a) H-SSI

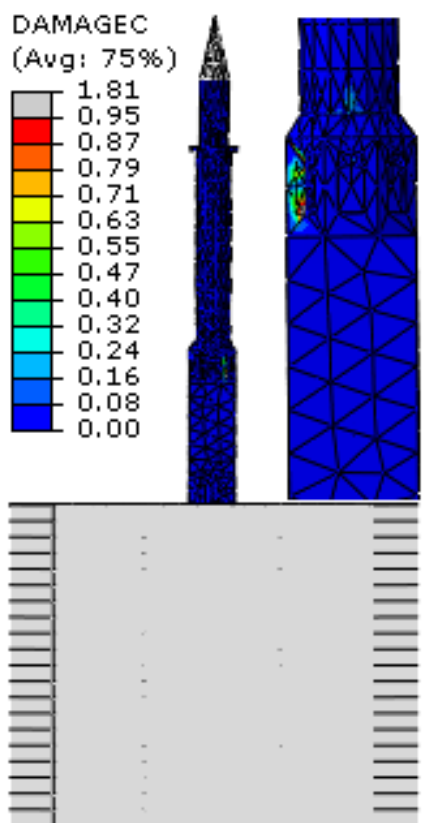

(b) S-SSI
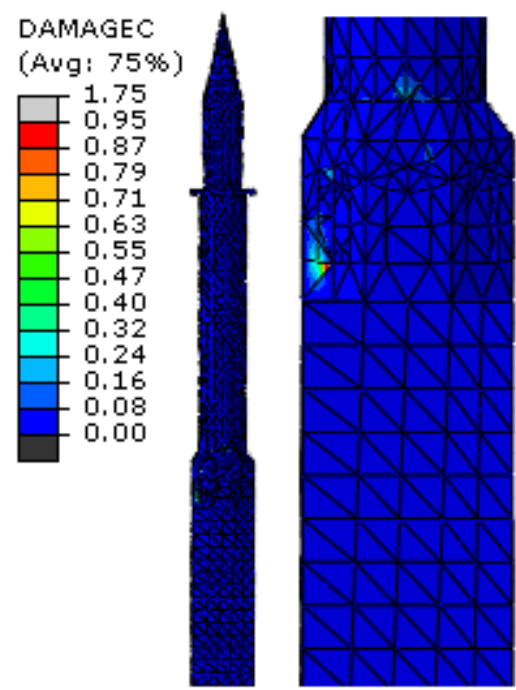

(c) F-S

Fig. 18. Distribution and ratios of compression damage on the minaret

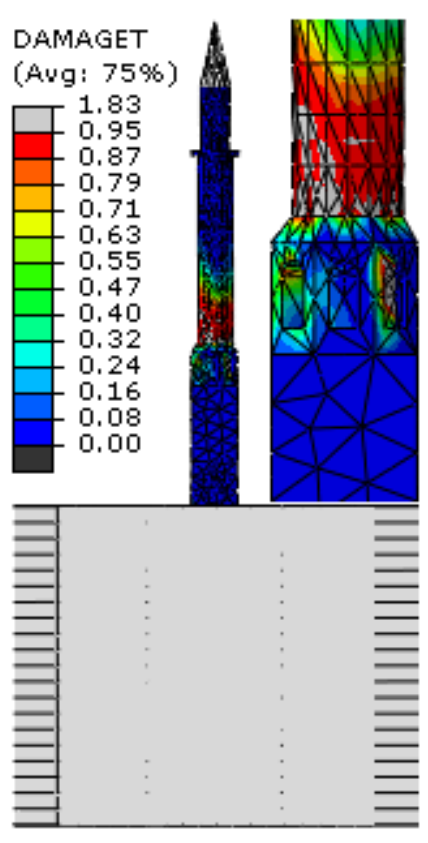

(a) H-SSI

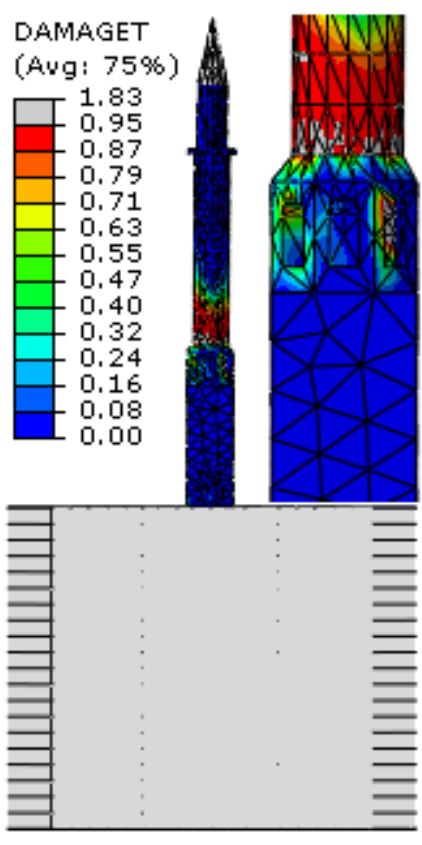

(b) S-SSI
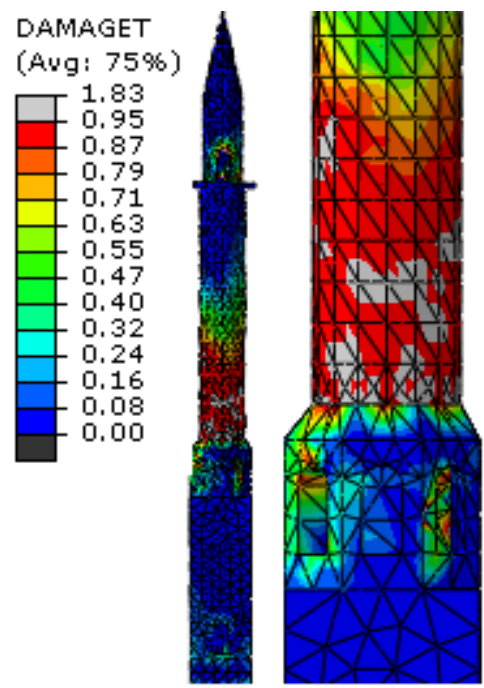

(c) F-S

Fig. 19. Distribution and ratios of tensile damage on the minaret 


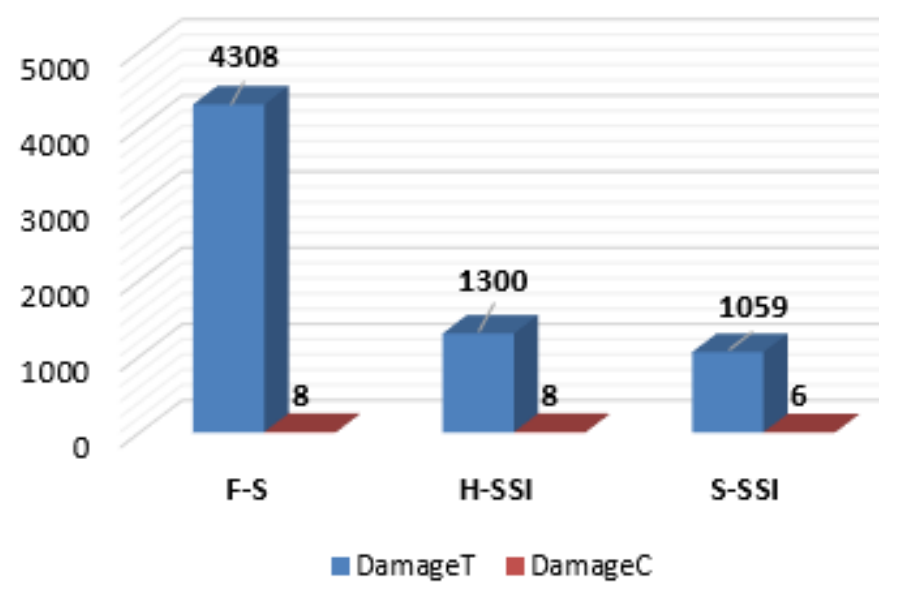

Fig. 20. Number of elements heavily damaged with compression and tensile stresses

\section{Conclusions}

The stone masonry minaret's structural behavior of the historical Ibrahim Celebi Mosque is investigated in this study. The slender minaret's initial FE model is improved with the OMA method. The differences between the frequency values of initial and calibrated FE model decreased from $34 \%$ to $0.6 \%$. This model is created by considering soil-structure interaction and analyzed with the nonlinear time history method. For material modeling, the CDP method is used. As a result of the analyses, top displacements, interstory drifts, stresses, and damage distributions of the minaret are obtained by considering different base conditions. Max interstory drifts form in the S-SSI model, and min interstory drifts occur in the F-S model. Interstory drifts increase with the decrease of the soil medium's stiffness. The number of elements that exceeded the limit tensile plastic strain is the highest in the F-S model, and it decreases in the S-SSI model. Forming due to tensile stresses, damages reach the maximum number in the F-S model and the minimum number in the S-SSI model. While the number of damaged elements in the models with soil media are similar, the number of elements with tensile damage in the F-S model is $69.8 \%$ higher than the H-SSI model and $75.4 \%$ more than the S-SSI model. The number of elements damaged by compressive stress was quite similar in all three models, and the S-SSI model get the least damage. Compressive and tensile principal stresses generally concentrate on the transition segment of the minaret. In case of a severe earthquake such as the Kocaeli earthquake, it is understood that especially tensile stresses can cause heavy damage to the minaret. From the seismic analyses results, it is observed that the soil medium has significant effects on structural behavior, especially the damage rates and distribution. It is concluded that SSI should be considered in numerical modeling and seismic analyses of especially historical structures. In addition, FE models should be calibrated by experimental methods such as ambient vibration tests in order to obtain the reliable numerical results.

\section{Declaration of conflicting interests}

The author(s) declared no potential conflicts of interest with respect to the research, authorship, and/or publication of this article.

\section{References}

[1] Adam MA, El-Salakawy TS, Salama MA, Mohamed AA (2020) Assessment of structural condition of a historic masonry minaret in Egypt. Case Stud Constr Mater 13:e00409.

[2] De Roeck G, Degrande G, Lombaert G, Müller G (2011) Dynamic modeling and testing of cablestayed pedestrian bridge. Proceedings of the $8^{\text {th }}$ 
International Conference on Structural Dynamics, EURODYN 2011 Leuven, Belgium.

[3] Dooms D, Degrande G, De Roeck G, Reynders E (2006) Finite element modelling of a silo based on experimental modal analysis. Eng Struct 28(4):532-542.

[4] Luz E, Gurr-Beyer C, Stöcklin W (1984) Experimental investigation of natural frequencies and modes of the HDR nuclear power plant by means of microtremor excitation. $8^{\text {th }}$ WCEE San Francisco, CA.

[5] Altunışık AC, Bayraktar A, Genc AF (2016) A study on seismic behaviour of masonry mosques after restoration. Earthq Struct 10(6):1331-1346.

[6] Bayraktar A, Altunişik AC, Sevim B, Türker T, Akköse M, Çoşkun N (2008) Modal analysis, experimental validation, and calibration of a historical masonry minaret. J Test Eval 36(6):516524.

[7] Demir A, Nohutcu H, Ercan E, Hokelekli E, Altintas G (2016) Effect of model calibration on seismic behaviour of a historical mosque. Struct Eng Mech 60(5):749-760.

[8] Ertek E, Fahjan MY (2007) Structural system of Ottoman minarets; classification, modelling and analysis. In: Sixth National Conference on Earthquake Engineering, İstanbul, p. 16-20.

[9] Nohutcu H, Demir A, Ercan E, Hokelekli E, Altintas G (2015) Investigation of a historic masonry structure by numerical and operational modal analyses. Struct Des Tall Spec Build 24(13):821-834.

[10] Nohutcu H, Hokelekli E, Ercan E, Demir A, Altintas G (2017) Collapse mechanism estimation of a historical slender minaret. Struct Eng Mech 64(5):653-660.

[11] Bernardeschi K, Padovani C, Pasquinelli G (2004) Numerical modelling of the structural behaviour of Buti's bell tower. J Cult Herit 5(4):371-378.

[12] Gani E, Erdoğan YS, Koçak A (2020) Evaluation of existing damage patterns and seismic assessment of historical Davutpasa barracks via operationalmodal analysis. J Perform Constr Facil 34(4):04020067.

[13] Hökelekli E, Demir A, Ercan E, Nohutçu H, Karabulut A (2020) Seismic assessment in a historical masonry minaret by linear and non-linear seismic analyses. Period Polytech Civ Eng 64(2):438-448.

[14] Rashidi M, Sharafi P, Alembagheri M, Bigdeli A, Samali B (2020) Operational modal analysis, testing and modelling of prefabricated steel modules with different LSF composite walls. Materials (24):5816.

[15] Aloisio A, Di Pasquale A, Alaggio R, Fragiacomo M (2020) Assessment of seismic retrofitting interventions of a masonry palace using operational modal analysis. Int $\mathrm{J}$ Archit Herit DOI: 10.1080/15583058.2020.1836531.

[16] Foti D, Giannoccaro NI, Vacca V, Lerna M (2020) Structural operativity evaluation of strategic buildings through finite element (FE) models validated by operational modal analysis (OMA). Sensors 20(11):3252.

[17] Güneş S, Anil Ö, Ghoroubi R, Mercimek Ö (2021) Determination of dynamic behavior of masonry structure using with operational modal analysis technique. Arab J Sci Eng 1-15.

[18] Nohutcu H (2019) Seismic failure pattern prediction in a historical masonry minaret under different earthquakes. Adv Civ Eng 2019:8752465.

[19] Casolo S, Diana V, Uva G (2017) Influence of soil deformability on the seismic response of a masonry tower. Bull Earthq Eng 15(5):1991-2014.

[20] Hökelekli E, Al-Helwani A (2020) Effect of soil properties on the seismic damage assessment of historical masonry minaret-soil interaction systems. Struct Des Tall Spec Build 29(2):e1694.

[21] Mina D, Forcellini D (2020) Soil-structure interaction assessment of the 23 November 1980 Irpinia-Basilicata earthquake. Geosciences 10(4): 152.

[22] Piro A, de Silva F, Parisi F, di Santolo AS, Silvestri F (2020) Effects of soil-foundation-structure interaction on fundamental frequency and radiation damping ratio of historical masonry building substructures. Bull Earthq Eng 18(4):1187-1212.

[23] Camata G, Cifelli L, Spacone E, Conte J, Torrese P (2008) Safety analysis of the bell tower of S. Maria Maggiore Cathedral in Guardiagrele (Italy). In: Proceedings of the $14^{\text {th }}$ World Conference on Earthquake Engineering, Beijing, China, p. 12-17.

[24] Hacıefendioğlu K (2010) Seasonally frozen soil's effect on stochastic response of masonry minaretsoil interaction systems to random seismic excitation. Cold Reg Sci Technol 60(1):66-74.

[25] Pitilakis D, Karatzetzou A (2015) Dynamic stiffness of monumental flexible masonry foundations. Bull Earthq Eng 13(1):67-82.

[26] de Silva F, Ceroni F, Sica S, Silvestri F (2018) Nonlinear analysis of the Carmine bell tower under seismic actions accounting for soil-foundation- 
structure interaction. Bull Earthq Eng 16(7):27752808.

[27] Ismail S, Kaddah F, Raphael W (2020) Seismic soil-structure interaction response of mid-rise concrete structures on silty sandy soil. Jordan J Civ Eng 14(1):117-135.

[28] Fathi A, Sadeghi A, Azadi MRE, Hoveidae N (2020) Assessing the soil-structure interaction effects by direct method on the out-of-plane behavior of masonry structures (case study: ArgeTabriz). Bull Earthq Eng 18(14):6429-6443.

[29] Scarfone R, Morigi M, Conti R (2020) Assessment of dynamic soil-structure interaction effects for tall buildings: A 3D numerical approach. Soil Dyn Earthq Eng 128:105864.

[30] ABAQUS (2012) Simulia Inc. Version 6.12. Providence, Rhode Island, USA.

[31] Turk AM, Cosgun C (2012) Seismic behaviour and retrofit of historic masonry minaret. Gradevinar 64(1):39-45.

[32] Lourenco PB (1996) Computational strategies for masonry structures. PhD Dissertation, Delft University of Technology, Netherlands.

[33] Öztürk Ş, Bayraktar A, Hökelekli E, Ashour A (2020) Nonlinear structural performance of a historical brick masonry inverted dome. Int J Archit Herit 14(8):1161-1179.

[34] Valente M, Milani G (2019) Advanced numerical insights into failure analysis and strengthening of monumental masonry churches under seismic actions. Eng Fail Anal 103:410-430.

[35] Valente M, Milani G (2019) Damage assessment and collapse investigation of three historical masonry palaces under seismic actions. Eng Fail Anal 98:10-37.

[36] Structural Vibration Solutions A/S ARTeMIS Mosal [Internet]. Available from: http://www.svibs.com

[37] Resta M, Fiore A, Monaco P (2013) Non-linear finite element analysis of masonry towers by adopting the damage plasticity constitutive model. Adv Struct Eng 16(5):791-803.

[38] Valente M, Milani G (2016) Non-linear dynamic and static analyses on eight historical masonry towers in the North-East of Italy. Eng Struct 114:241-270.
[39] Bayraktar A, Hökelekli E, Halifeoğlu FM, Mosallam A, Karadeniz H (2018) Vertical strong ground motion effects on seismic damage propagations of historical masonry rectangular minarets. Eng Fail Anal 91:115-128.

[40] Tiberti S, Acito M, Milani G (2016) Comprehensive FE numerical insight into Finale Emilia Castle behavior under 2012 Emilia Romagna seismic sequence: Damage causes and seismic vulnerability mitigation hypothesis. Eng Struct 117:397-421.

[41] Kramer SL (1996) Geotechnical Earthquake Engineering. Pearson Education, India.

[42] Maheswari RU, Boominathan A, Dodagoudar GR (2010) Seismic site classification and site period mapping of Chennai City using geophysical and geotechnical data. J Appl Geophys 72(3):152-168.

[43] Abbas AL Saeed MH (2019) Simulation two storey house of masonry wall under the earthquake load. Diyala J Eng Sci 12(2):1-12.

[44] Altunişik AC, Okur FY, Genç AF, Günaydin M, Adanur S (2018) Automated model updating of historical masonry structures based on ambient vibration measurements. J Perform Constr Facil 32(1):04017126.

[45] Aşıkoğlu A, Avşar Ö, Lourenço PB, Silva LC (2019) Effectiveness of seismic retrofitting of a historical masonry structure: Kütahya Kurşunlu Mosque, Turkey. Bull Earthq Eng 17(6):3365-95.

[46] Elyamani A, Roca Fabregat P, Caselles Magallón JO, Clapes Boixader J (2019) Evaluation of Mallorca Cathedral seismic behavior using different analysis techniques. Mediterr Archaeol Archaeom 19(1):41-60.

[47] Fathi A, Sadeghi A, Emami Azadi MR, Hoveidaie N (2020) Assessing seismic behavior of a masonry historic building considering soil-foundationstructure interaction (Case Study of Arge-Tabriz). Int J Archit Herit 14(6):795-810.

[48] Hashash YMA, Musgrove MI, Harmon JA, Groholski DR, Phillips CA, Park D (2016) DEEPSOIL 6.1, User Manual. Urbana IL Board Trustee University of Illinois at UrbanaChampaign. 